\title{
Two-Phase Flow CFD Analysis of Temperature Effects on Oil Supplied to Small-Bore Journal Bearing with Oil Supply Groove
}

\author{
Fuma Sakai $^{1}$, Masayuki Ochiai ${ }^{2 *}$ and Hiromu Hashimoto ${ }^{2)}$ \\ ${ }^{1)}$ Graduate School of Science and Technology, Tokai University, 4-1-1 Kitakaname, Hiratsuka, Kanagawa Prefecture 259-1292, Japan \\ ${ }^{2)}$ Department of Mechanical Engineering, Tokai University, 4-1-1 Kitakaname, Hiratsuka, Kanagawa Prefecture 259-1292, Japan \\ *Corresponding author: Masayuki Ochiai (ochiai-m@tsc.u-tokai.ac.jp)
}

Manuscript received 01 May 2018; accepted 30 August 2018; published 31 October 2018

\begin{abstract}
Oil whips might present a risk that is associated with bearing seizures. To conveniently suppress oil whips, a stabilization method using starved lubrication has been proposed. As the oil film becomes thinner, an increase in oil film temperature is expected. In this study, the bearing temperature was studied in the cases of oil whip, transition condition, and starved lubrication. Moreover, the temperature distributions in the transition and starved lubrication conditions were studied using a two-phase flow computational fluid dynamics (CFD) analysis. As a result, it was found that the heat amount due to shear friction was small in the case of the transition condition, whereas the temperature inside the bearing was approximately the same as that of the supply oil, from both experimental and analytical perspectives. In the case of the starved lubrication condition, it was found that the air flowing out of the oil supply groove created a circulated flow, which cooled the side end of the bearing, thereby controlling the temperature at the center of the bearing.
\end{abstract}

\section{Keywords}

journal bearing, bearing temperature, small-bore, oil whip, starved lubrication, oil control, two-phase flow CFD analysis

\section{Introduction}

An oil whip is an excited vibration caused by the oil film reaction of a journal bearing. An oil whip has the risk of bearing seizure and machinery breakdown. Journal bearings are widely used as support elements for high-speed rotating machinery, such as compressors, turbines, and pumps. Therefore, the suppression of oil whips has become extremely important in bearing design. In order to control oil whips, tilting pad bearings are traditionally used, but these bearings have a complicated structure combined with high cost, and their application in small-size rotating machinery is not always appropriate. By contrast, it was found that the stability characteristics of a bearing are improved by changing its shape and installation angle, but these methods do not have the same stability as tilting pad bearings [1-3]. On the other hand, Hashimoto and Ochiai proposed a stabilization method using starved lubrication. They found that a journal bearing under starved lubrication has the same high stability as a tilting pad bearing, both theoretically and experimentally [4, 5]. Furthermore, Heshmat found that the starved lubrication condition is able to reduce the bearing friction loss because the gas phase is broadened by the reduced supply of oil [6]. However, an increasing oil film temperature is expected as the oil film becomes thin, as in the case of starved lubrication. The distribution of bearing temperature under starved lubrication is believed to be different from the traditional distribution because of an increase of the gas phase in the bearing and oil filler port. Therefore, the temperature distribution under starved lubrication is required to comprehend all regions of a bearing. On the subject of temperature measurements in journal bearings, Mitsui used a sophisticated experiment to study the influence of the eccentricity ratio, amount of supply oil, and oil viscosity on the temperature of a journal bearing and viewed the cavitation $[7,8]$. However, these results were under static conditions, and the temperature distribution in all regions of a bearing under starved lubrication and during an oil whip event have not been investigated. By contrast, the transition region exists in the process between an oil whip condition and stabilization by starved lubrication. In this region, an oil whip can be suppressed while maintaining the oil film thickness. Even though the transition region has a risk that an oil whip will be generated by a new large external vibration, the authors believe that by actively controlling the supply oil, it will actually be possible to utilize the transition region.

Therefore, in this study, the oil film temperature was measured at points on the bearing centerline and at points on a line halfway between the centerline and side end, in the cases of the oil whip condition, transition region, and starved lubrication condition. The gas phase area in the bearing was also viewed. 
In addition, the temperature distributions in a journal bearing under transition condition and starved lubrication were studied analytically. Gas phase areas such as the cavitation and air phases need to be considered in a thermal analysis of a journal bearing in the cases of starved lubrication and transition condition. Generally, the Reynolds equation has been used to analyze journal bearings and the simplest method for determining the cavitation area is to consider the halfSommerfeld or Swift and Stieber condition for the Reynolds equation. However, these methods ignore the oil film spreading clearance because the negative pressure area is assumed to be in the cavitation area. Therefore, boundary condition models considering cavitation have been proposed by many researchers. For example, Ikeuchi and Mori analyzed the areas of oil film and cavitation using a modified Reynolds equation [9, 10]. The modified Reynolds equation is derived by considering two-phase flow as the averaged single-phase flow of oil and air. Nevertheless, it is difficult to converge the theoretical model in the cases of high eccentricity ratio and starvation lubrication conditions using the model of Ikeuchi and Mori. By contrast, Hatakenaka et al. proposed an analytical method by assuming of the shape of finger-type cavitation [11]. However, the internal flow in the oil filler port and bearing clearance cannot be solved using the Reynolds equation. Therefore, a different approach is required to analyze the journal bearing and internal flow of the oil filler port.

In recent years, two-phase flow computational fluid dynamics (CFD) analyses considering of the vapor pressure and interfacial transport equation have been proposed. For example, the volume of fluid (VOF) method has good convergence with other methods, and it can evaluate bearings in a relatively shorter time. Moreover, the VOF method is easily adapted to a journal bearing's environment, because it has an advantage for analyzing the slag flow. To date, analysis with the VOF method has been used for studying the characteristics of journal bearings with reported analytical results. For example, Zhai et al. and Dhande et al. analyzed the cavitation area of a journal bearing using the VOF method in consideration of vapor pressure $[12,13]$. However, the conditions of the transition region and starved lubrication have not been analyzed yet. Incidentally, authors have analyzed journal bearings under starved lubrication [14] and have discussed the effects of the internal flow of the oil filler port on the stability characteristics under that condition [15].

Against these backgrounds, this study analyzed, the temperature distribution in a journal bearing under the transition and starved lubrication conditions using a two-phase flow CFD analysis for which the calculation conditions had been decided on the basis of experiments.

\section{Experimental setup}

\subsection{Test bearing and test rig}

Figure 1 shows the geometry of the experimental setup used in the experiments. Its main dimensions are provided in Table 1. The upper part of the test bearing is equipped with an oil filler port, which directs supply oil into the bearing clearance. The bearing diameter $D$, bearing clearance $C_{r}$, bearing width $L$, oil filler port diameter $D_{p}$, and width-diameter ratio $\lambda$ are $25.0 \mathrm{~mm}$, $175 \mu \mathrm{m}, 14.5 \mathrm{~mm}, 8.2 \mathrm{~mm}$, and 0.58 , respectively. The bearing was made of transparent acrylic, allowed observation of the formation of the oil film and the generation of cavitation.

Figure 2 shows a schematic diagram of the overall experimental test rig. It consists of a revolving shaft supported by two bearings on its left and right ends. The test bearing is installed on the right end of the shaft. A rotor is located at the

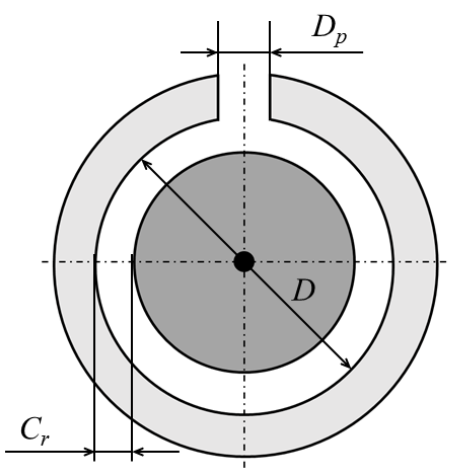

Fig. 1 Geometry of bearing

Table 1 Bearing specifications

\begin{tabular}{l|l}
\hline \hline Diameter $D, \mathrm{~mm}$ & 25.0 \\
\hline Width length $L, \mathrm{~mm}$ & 14.5 \\
\hline Clearance $C_{r}, \mu \mathrm{m}$ & 175 \\
\hline Diameter of oil filler port $D_{p}, \mathrm{~mm}$ & 8.2 \\
\hline Width/diameter ratio, $L / D$ & 0.58 \\
\hline \hline
\end{tabular}

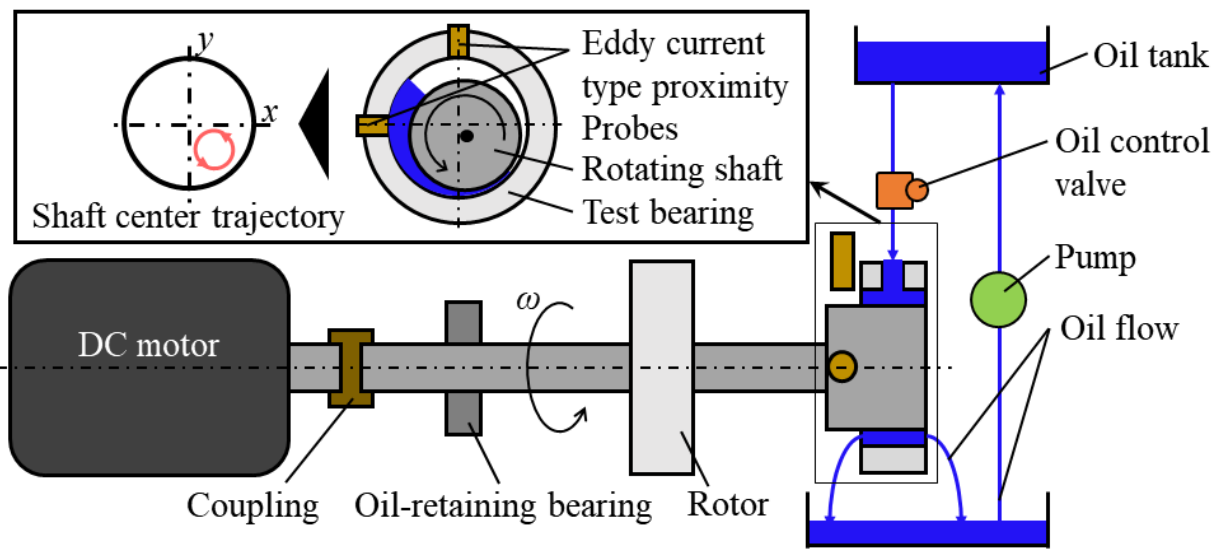

Fig. 2 Geometry of experimental test rig 

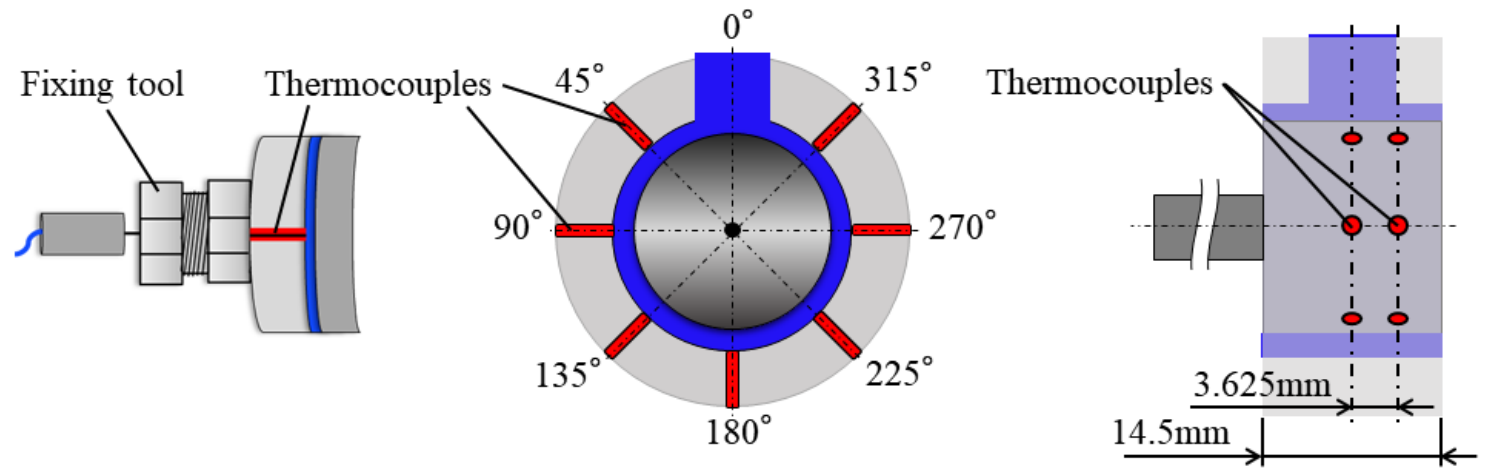

Fig. 3 Setting positions of thermocouples in bearing

midpoint of the shaft. The bearing load in this study is $4.24 \mathrm{~N}$. The shaft is driven by a DC motor, which can continuously control the number of revolutions up to 10,000 rpm. Eddycurrent-type proximity probes are inserted into the bearing in the horizontal and vertical directions, to allow measurement of the journal position. An oil tank is located above the bearing, and the lubricating oil is supplied through a control valve. Oil leaking from the side ends of the bearing is returned to the oil tank through the pump. The viscosity grade of lubricant oil was VG22. The use of a blue lubricant oil containing xylene made it possible to view the region where cavitation was generated. The amount of oil leaking from the side ends of the test bearing was measured by manually changing the opening of the control valve. A halogen light was used as a light source to view the gas phase area on the surface of the bearing.

\subsection{Measurement of bearing temperature}

In this study, the temperature in the bearing clearance was measured using sheathed thermocouples. Figure 3 shows the positions of the thermocouples in the bearing. They are installed two lines of bearing centerline and halfway between the center and side end of the bearing and are positioned $45^{\circ}$ apart on the bearing's circumference. Thus, the temperatures in the bearing clearance were measured at a total of 14 locations. Moreover, the thermocouples were installed obliquely on the bearing in order to be able to view the experiment at the same time. It was found in previous experiments that the temperature measurement error was almost negligible in the case of obliquely installed thermocouple. The thermocouples were secured by feedthroughs, and oil leakage through the insertion hole was prevented by applying a sealant. As the experimental method, the temperature of the supplied oil was fixed at $40^{\circ} \mathrm{C}$ by a heater, while the rotating speed of the shaft was increased to 7,500 rpm. In this study, the temperature in the bearing clearance was measured in the oil whip, transition, and starved lubrication conditions. Moreover, oil whip is defined as the occurrence of a large whirling motion generated when the amount of supply oil is increased from a stable state of the shaft by a decrease in amount of supply oil. By contrast, the transition region is defined as the stable state at the maximum of amount of supply oil when oil decreases from the oil whip condition. Finally, the starved lubrication condition is defined as the condition of absolute stability at the maximum of amount of supply oil when the supply oil decreases from the transition region. Based on these definitions, the temperatures in the bearing clearance in the case of the oil whip, transition, and starved lubrication conditions were measured. Temperatures were measured continuously for five minutes, and the temperature results are their average values. The ambient temperature was a constant $25^{\circ} \mathrm{C}$.

\section{CFD analysis method}

In this study, the journal bearing was analyzed using the FLUENT 17.0 simulation software. Instead of the Reynolds equation, the Navier-Stokes equation was used to analyze the journal bearing. A CFD analysis is able to analyze the internal flow of the oil filler port because the inertia term is considered in the basic equation. Moreover, pressure changes in the direction of the bearing clearance can be calculated.

Figure 4 shows the bearing calculation model for the CFD analysis. The bearing clearance, oil filler port, and oil supply groove are modeled, and the overall flow in the bearing can be calculated. The calculation model is configured as symmetrical from the center of bearing. Its dimensions are the same as those of the test bearing. Table 2 shows the oil supply flow $Q$, eccentricity $\varepsilon$, and attitude angle $\varphi$ of the calculation model. These values were determined based on the experimental results. The computational grid was set at four layers in the direction of the bearing clearance. The number of meshes of transition region was $71 \times 10^{5}$, and that of the starved lubrication condition was $68 \times 10^{5}$.

Table 3 shows the calculation conditions. In this study, the VOF method was used to analyze the journal bearing. Concerning surface tension, the tension between the oil and air were also considered. The value of the surface tension was set at $0.04 \mathrm{~N} / \mathrm{m}$ and was measured using the du Noüy method. The model of Brackbill [16] was used as the surface tension model. In the case considering vapor pressure, the volume of air dissolving in the oil phase expands when lower than vapor

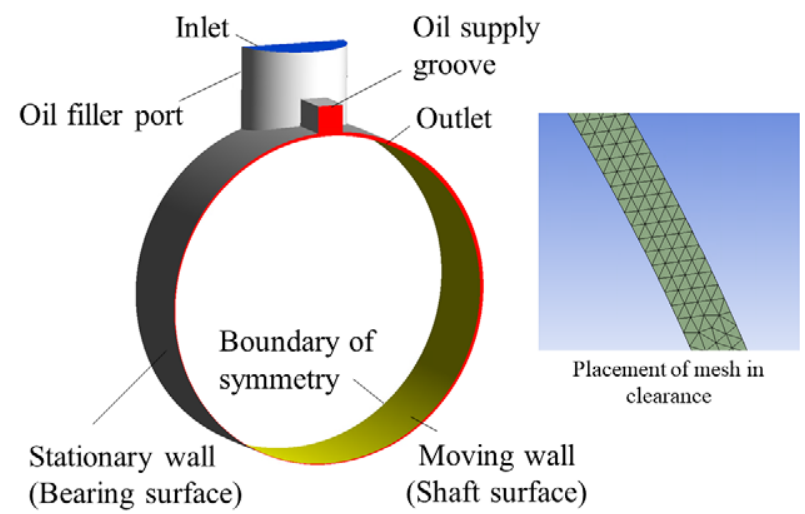

Fig. 4 Calculation model of bearing 
Table 2 Specifications of calculations model

\begin{tabular}{c|c|c|c}
\hline \hline & Oil supply amount $Q, \mathrm{~cm}^{3} / \mathrm{s}$ & Eccentricity $\varepsilon$ & Attitude angle $\varphi$, deg. \\
\hline Transition region & 3.7 & 0.47 & 66.9 \\
\hline Starved lubrication & 0.5 & 0.83 & 43.3 \\
\hline \hline
\end{tabular}

Table 3 Calculating condition

\begin{tabular}{|c|c|c|c|}
\hline \multicolumn{3}{|l|}{ Multiphase model } & Volume of fluid \\
\hline \multirow{2}{*}{\multicolumn{2}{|c|}{ Phase condition }} & Vapor pressure $P_{v}, \mathrm{~Pa}$ & 0 \\
\hline & & Surface tension $S, \mathrm{~N} / \mathrm{m}$ & 0.04 \\
\hline \multirow{10}{*}{ Fluid Properties } & \multirow{5}{*}{ Oil } & Temperature $T,{ }^{\circ} \mathrm{C}$ & 40 \\
\hline & & Density $\rho, \mathrm{kg} / \mathrm{m}^{3}$ & 860 \\
\hline & & Viscosity $\mu, \mathrm{Pa} \cdot \mathrm{s}$ & 0.019 \\
\hline & & Thermal conductivity $\varphi, \mathrm{W} / \mathrm{m} \cdot \mathrm{K}$ & 0.131 \\
\hline & & Specific heat $C_{p}, \mathrm{~J} / \mathrm{kg} \cdot \mathrm{K}$ & 1950 \\
\hline & \multirow{5}{*}{ Air } & Temperature $T,{ }^{\circ} \mathrm{C}$ & 28 \\
\hline & & Density $\rho, \mathrm{kg} / \mathrm{m}^{3}$ & 1.23 \\
\hline & & Viscosity $\mu, \mathrm{Pa} \cdot \mathrm{s}$ & $1.75 \times 10^{-5}$ \\
\hline & & Thermal conductivity $\varphi, \mathrm{W} / \mathrm{m} \cdot \mathrm{K}$ & 0.024 \\
\hline & & Specific heat $C_{p}, \mathrm{~J} / \mathrm{kg} \cdot \mathrm{K}$ & 1006.43 \\
\hline
\end{tabular}

pressure. Moreover, The model of Schnerr and Sauer [17] was used as the cavitaion model. In this study, the value of the vapor pressure was set to zero. Moreover, the VOF function considering these conditions of gas-liquid was calculated by first-order up wind. The properties of oil and air are suggested in Table 3. In the VOF method considering the vapor pressure, when the volume fraction decreases due to the vapor pressure, the fluid property make a transition from oil to air. The viscosity that is important for the viscous heating term in the energy equation depends on the volume fraction, so the heat generation due to friction decreases as the volume fraction decreases. In this study, it was believed that the property effects were only slightly varied by the pressure and temperature because the analysis involved a relatively small bearing. Therefore, the change in pressure and temperature caused by the property effects were ignored.

For the boundary conditions of the calculations, the inlet velocity was set based on the oil supply amount from the experimental results. The temperature of oil from the inlet was $40^{\circ} \mathrm{C}$, as in the experimental environment, and the outlet was set to counterflow only in the gas phase. Also, the temperature of the counter flow was $25^{\circ} \mathrm{C}$, as in the experimental environment. The shaft was set to rotate at 7,500 rpm. The mean temperature at the wall of the shaft surface, obtained from the experiments, was set as the thermal boundary condition of the rotating shaft. The wall of the shaft surface was analyzed to determine the heat flux. The mean temperature at the shaft surface under starved lubrication is $42.5^{\circ} \mathrm{C}$, and transition condition is $40.5^{\circ} \mathrm{C}$.
On the other hand, the external convection heat transfer was used as the thermal boundary condition of the bearing surface. Thus, the thickness of bearing, the heat transfer coefficient between the external wall of bearing and outside air, the heat conductivity of the bearing, and the specific heat of the bearing were set. Furthermore, the temperature at the bearing surface was analyzed. In this study, these values were set as follows; the thickness of bearing is $22.5 \mathrm{~mm}$, the heat transfer coefficient between the external wall of bearing and outside is $5 \mathrm{~W} / \mathrm{m}^{2}-\mathrm{K}$, the thermal conductivity of the bearing is $0.17 \mathrm{~W} /$ $\mathrm{m}-\mathrm{K}$, and the specific heat of the bearing is $1470 \mathrm{~J} / \mathrm{kg}-\mathrm{K}$. The thermal conductivity and the specific heat of the bearing was determined based on the properties of acrylic, and the outside air was $25^{\circ} \mathrm{C}$ as in the experimental environment. Moreover, the wall surfaces of the oil filler port and oil supply groove were set using the same thermal boundary conditions. The convergence of the calculations became stable enough to analyze under these thermal boundary conditions and the temperature distribution in the bearing clearance could also be analyzed. The flow of oil was laminar, and the analysis conditions were at steady state. In this study, the equation of continuity and the Navier-Storks equation was solved by the SIMPLE method, and so too with the energy equation.

\section{Experimental results for temperature}

Figure 5 shows the experimental results of an oil whip event. Figure 5(a) presents the experimental temperature results. 
In this figure, the red plot presents the temperature at the center of the bearing, and the blue plot represents the temperature at a point between the center and side end. Figure 5(b) shows the results for the shaft center trajectories. The red line represents the position of the center of shaft, and the arrow indicates the direction of rotation. Figure 5(c) shows the observation results for the gas phase region. In this study, the observation results are shown because the gas phase region varies from moment to moment during high-speed rotation. The yellow area is the gas phase region, and the other region is the oil film. The dotted red

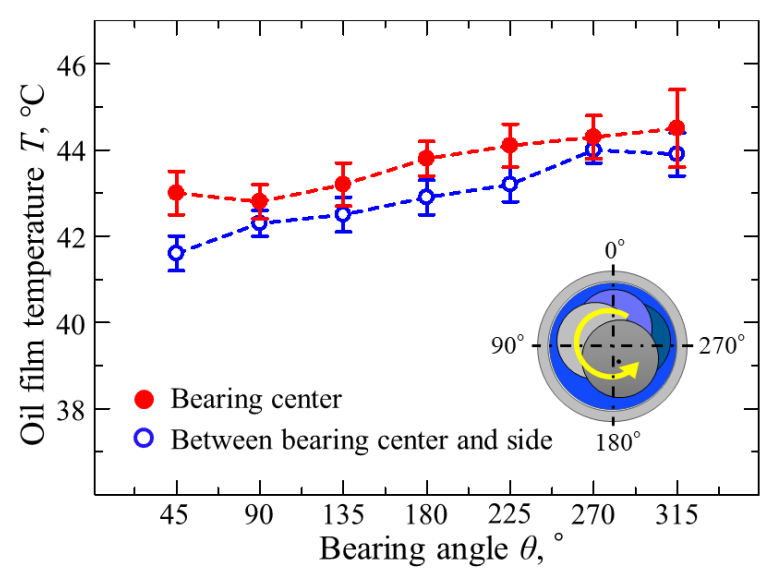

(a) Bearing temperature

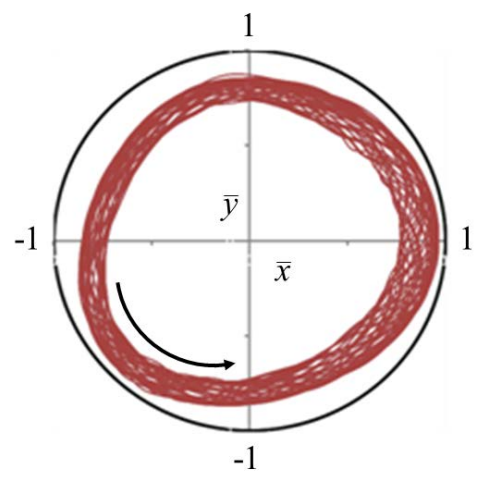

(b) Shaft center trajectory

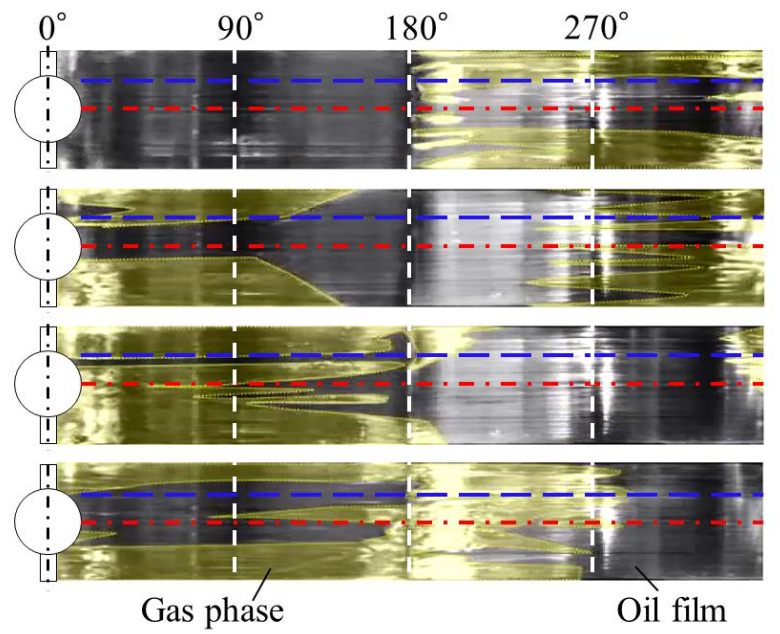

(c) Gas phase region

Fig. 5 Results for oil whip condition line represents the position of the center of the bearing, and the blue dashed line represents the intermediate position halfway between the center and side end.

Figure 5(a) shows that the temperature at the inside of the bearing, which was measured between the bearing angles of $45^{\circ}$ and $135^{\circ}$, rises in the $2^{\circ} \mathrm{C}$ to $4^{\circ} \mathrm{C}$ range in reaction to the supply oil at $40^{\circ} \mathrm{C}$. Because of the temperature increase at all of the measurement positions, it was believed that bearing temperature decreases caused by heat with generated for shear friction as the oil film became thin with the large shaft amplitude during an oil whip event, as shown in Fig. 5(b). Moreover, it is believed that the temperature decreased slightly with the mixing of the high-temperature circulating flow and supply oil within the oil filler port. In a comparison between the center of the bearing and the intermediate position, the temperature at the center of the bearing is higher than that at the intermediate position at all measurement points. However, based on the results for the bearing angles between $90^{\circ}$ and $180^{\circ}$, the temperatures at the intermediate position gradually increased compared with those at the center of the bearing. Moreover, in the results for the bearing angles between $270^{\circ}$ and $315^{\circ}$, the temperatures at the intermediate point decreased, whereas at the bearing angle position of $45^{\circ}$, the temperature at the intermediate point was $1.5^{\circ} \mathrm{C}$ lower than that at the center of the bearing. The reason is believed to be that the outside air flowing from the side end of the bearing by a large-amplitude inverse squeeze effect cooled the oil film. This is also suggested by the observation results shown in Fig. 5(c).

Figure 6 shows the experimental results for the transition condition. From Fig. 6(a), the temperature trend in the transition condition is far different from that in an oil whip event, and the temperature in the bearing clearance increases in a range that is not more than $1{ }^{\circ} \mathrm{C}$ in reaction to the $40^{\circ} \mathrm{C}$ supply oil. For this reason, the evolution of heat by shear friction is suppressed compared with that of an oil whip event because the oil film thickness is stably maintained in the case of the transition condition, as shown in Fig. 6(b). It is believed that the temperature elevation was suppressed by the cooling effect of the supply oil. On the other hand, the gas phase existed at the side end of the bearing and the intermediate position, at bearing angles between $0^{\circ}$ and $135^{\circ}$. It also existed at the center of the bearing and at all regions of the width of bearing at bearing angles between $270^{\circ}$ and $0^{\circ}$. However, the difference in temperature between the center of the bearing and the intermediate position was smaller compared with an oil whip event. This was due to a decrease in absorption of outside air caused by a decrease in the inverse squeeze effect. Therefore, it is believed that the gas phase in the transition condition is gas cavitation liberated from the oil by the depressurization at reverse wedge side. Gas cavitation depends on the temperature of the dissolving oil. Hence, it is believed that the oil film at the intermediate position was not cooled down at these points.

Figure 7 shows the experimental results for the starved lubrication condition. In Fig. 7(a), the temperature trend of the starved lubrication condition is extremely different from the oil whip and transition conditions. Moreover, the temperature is highest at a bearing angle of $225^{\circ}$ among all of the temperature measurement points. This is because the temperature of the oil film rose from the heat caused by shear friction at the position of minimum clearance in Fig. 7(b). Temperature at the center of the bearing are compared with those at the intermediate position. The temperatures at the intermediate position were higher than those at the center of the bearing 


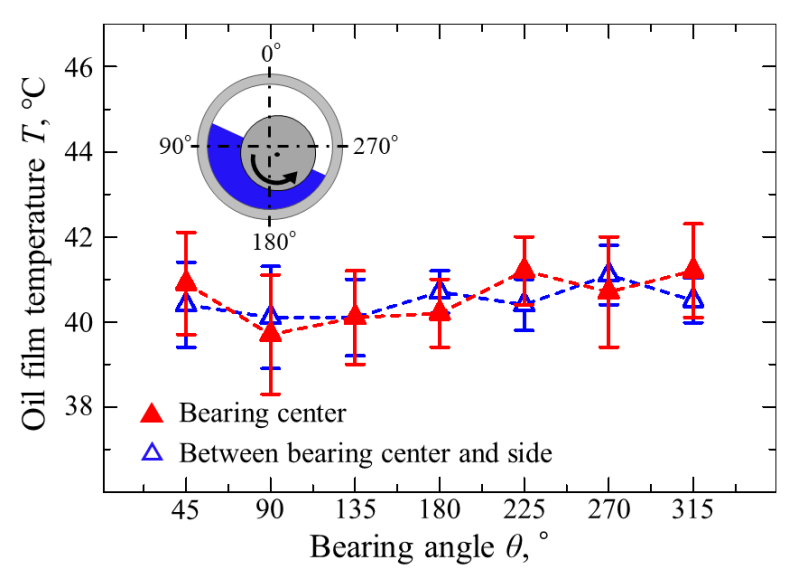

(a) Bearing temperature

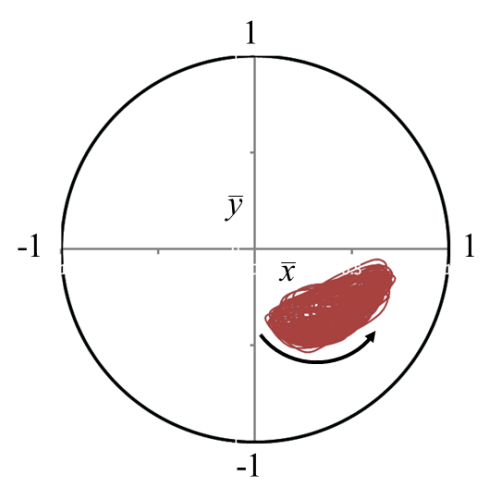

(b) Shaft center trajectory
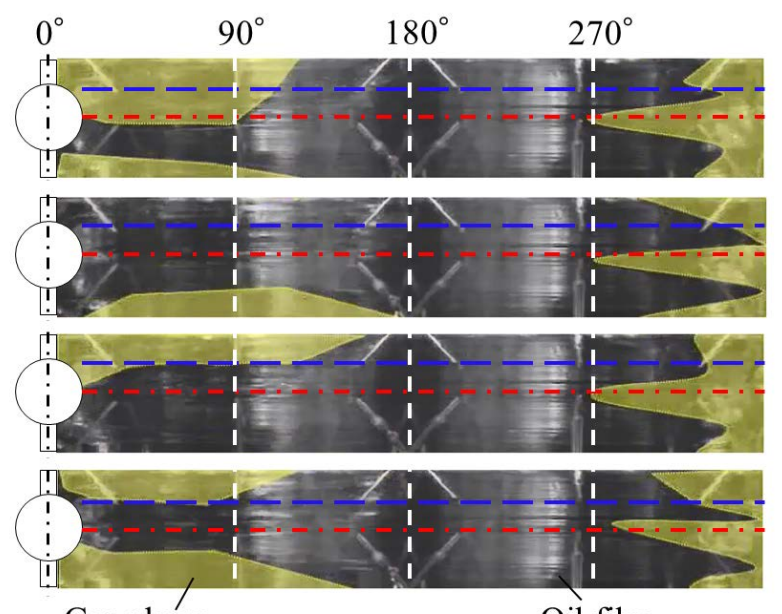

Gas phase

Oil film

(c) Gas phase region

Fig. 6 Results for transition condition

at points between $45^{\circ}$ and $270^{\circ}$. Therefore, the trend of the temperature distribution is different from typical trend of a journal bearing. In Fig. 7(c), the gas phase region in the starved lubrication condition increases compared with the case of the transition condition, but it becomes unstable at bearing angles between $0^{\circ}$ and $180^{\circ}$. Moreover, it is believed that the fraction of the gas phase is a major part of gas cavitation, as can be seen from the experimental temperature results for the transition condition, and since the temperature of gas cavitation at $315^{\circ}$ and the temperature at $45^{\circ}$ and $90^{\circ}$ are almost unchanged, it is considered that the gas cavitation circulated upstream of the

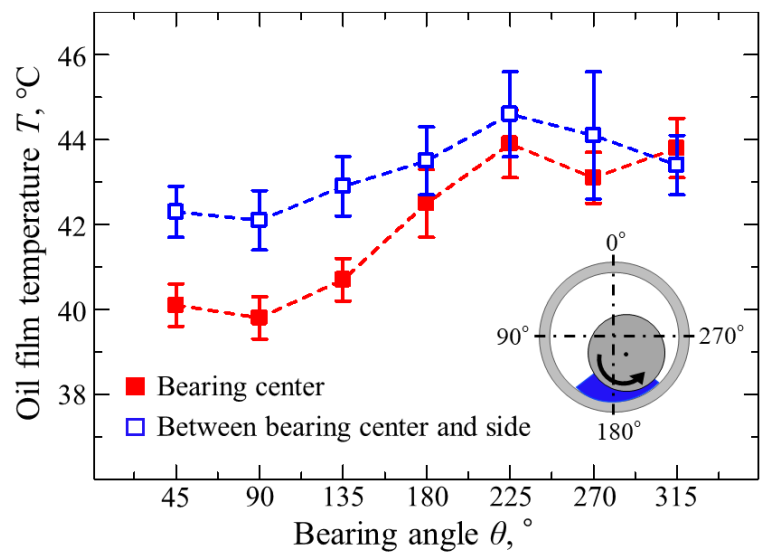

(a) Bearing temperature

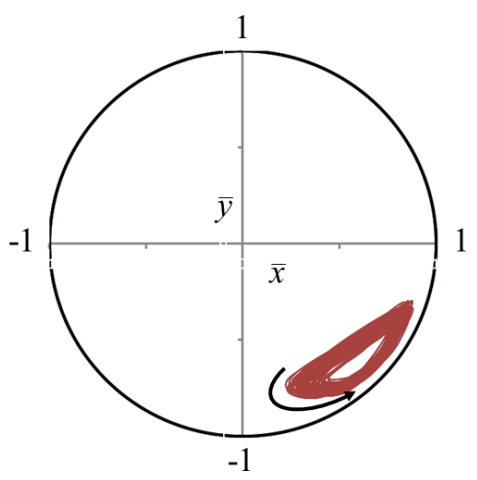

(b) Shaft center trajectory
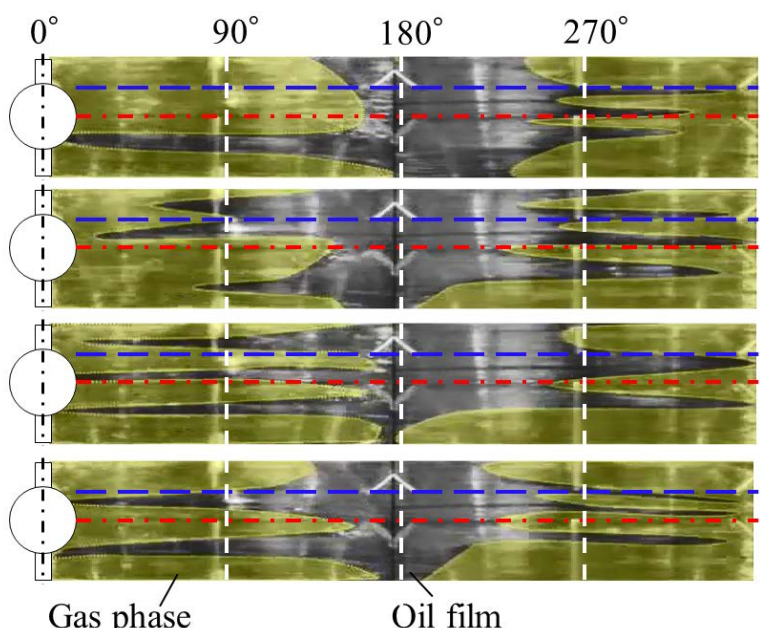

Gas phase

Oil film

(c) Gas phase region

Fig. 7 Results for starved lubrication condition

bearing. At the center of the bearing, the temperature between the $45^{\circ}$ and $90^{\circ}$ positions is $40^{\circ} \mathrm{C}$ despite the temperature at bearing angle $315^{\circ}$ being $44^{\circ} \mathrm{C}$. Thus, it was found that the increasing temperature caused by the circulating flow was controlled by the cooling effect of the supply oil.

\section{CFD analysis results}

Figure 8 shows the analysis results of temperature of the transition region in the same position of experiment. The red line indicates the analysis results of temperature at the center 


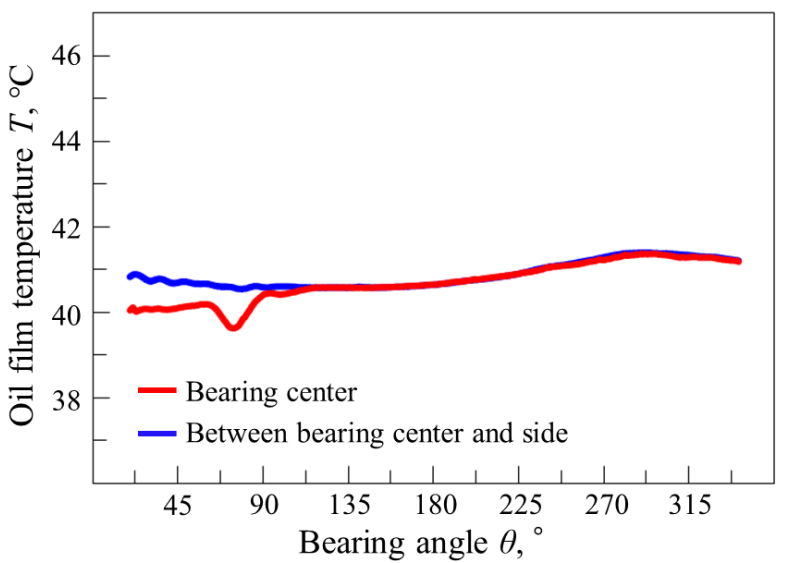

Fig. 8 Analysis result for temperature in transition region

of beating, while the blue line indicates the analytical results of the temperature at the intermediate between the center and the side end. In comparison of the analytical results and the experimental results, it is found that the analytical results are close to the experimental results. Thus, it is considered that the analysis method in this study is appropriate. Temperature is not really different at the bearing angle as with the experimental results, while it gradually rises the bearing angle between $180^{\circ}$ and $290^{\circ}$. Moreover, the difference in temperature of the center of bearing and the intermediate between the center and the side end is small at these areas, but the temperature of the intermediate between the center and the side end is higher compared to the temperature of the center of bearing. On the other hand, the difference of both values become large at the bearing angle between $22.5^{\circ}$ and $112.5^{\circ}$. Further, it is found that the temperature of the center of bearing gradually rises, while the temperature of the intermediate between the center and the side end gradually decreases. As for this reason, it is considered to the fact that the both values neared from the intermediate between the center and the side end to the center of bearing by the heat transfer. On the other hand, the different of both values become $1.5^{\circ} \mathrm{C}$.

Figure 9 shows the analytical results of the full-area of the bearing in the transition condition. Figure 9(a) indicates the analytical results of volume fraction distribution of oil. The red color means full oil and the blue color means full air. Figure 9(b) indicates the analytical results of temperature distribution of bearing. From Fig. 9(a), the volume fraction of the wedge side become zero at the side end. Thus, these areas are gas phase. Moreover, the volume fraction increases at the center of bearing. These trends are same as the experimental results. On the other hand, the volume fraction of the inverse wedge side decreases with increasing of clearance. From Fig. 9(b), the temperature slightly rises by the shear friction, but it is found that the temperature is almost $40^{\circ} \mathrm{C}$ at the full-area of the bearing. Thus, it is found that the heat quantity by the shear friction is small in the case of transition condition, while the temperature inside the bearing is approximately same as the temperature of supply oil from the experiment and analysts.

Figure 10 shows the analytical results of temperature under the starved lubrication condition in the same position of experiment. In comparison of the analytical results and the experimental results, it is found that the analytical results are qualitatively closely with the experimental results. From Fig. 10, the temperature is highest at the bearing angle $250^{\circ}$, while the different of the temperature of the center of bearing

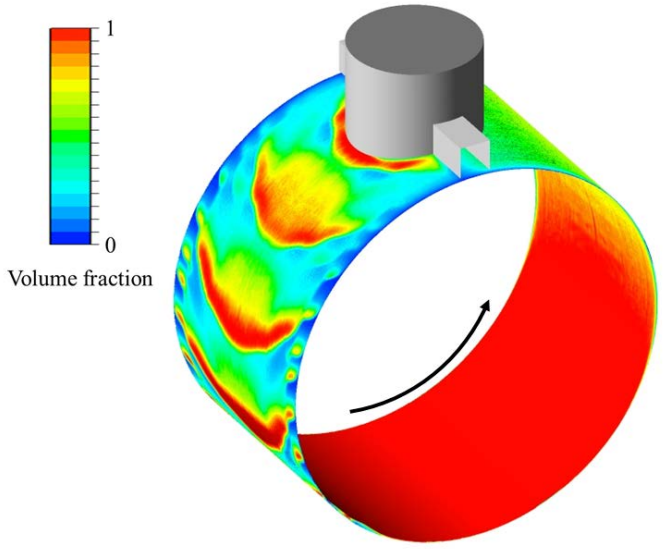

(a) Distribution of oil volume fraction

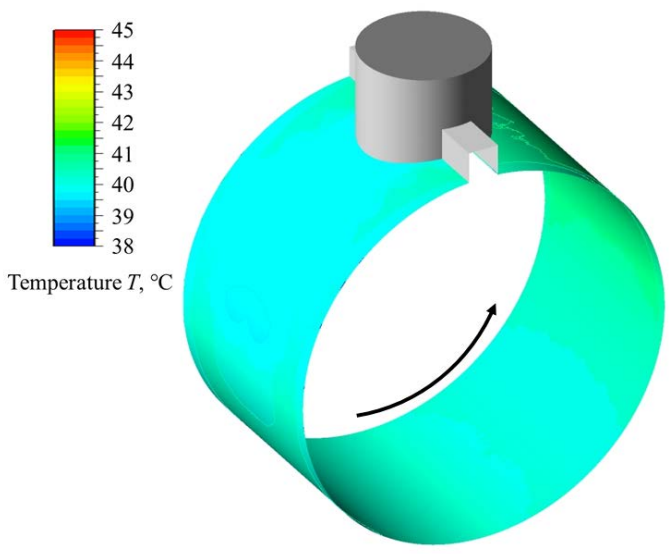

(b) Distribution of temperature

Fig. 9 Analysis results for transition condition

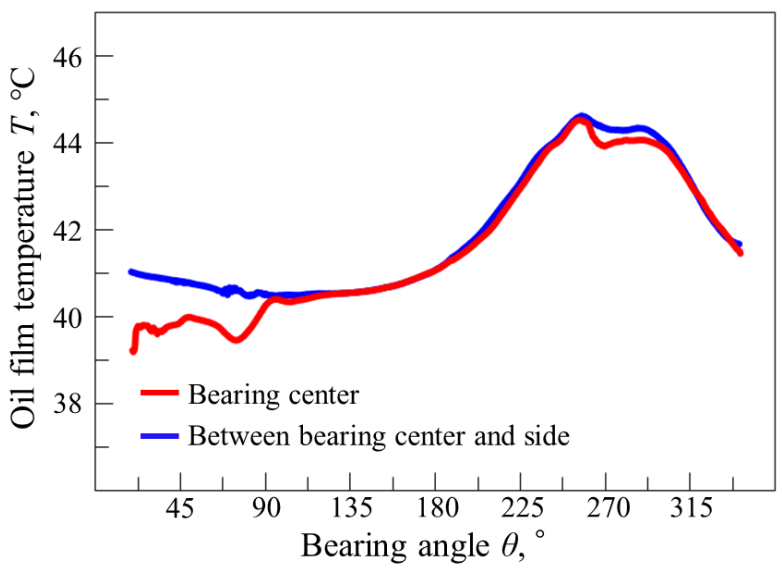

Fig. 10 Analysis result for temperature in starved lubrication condition

and the intermediate between the center and the side end is large compared to the transition condition. In comparison of the bearing angle $22.5^{\circ}$ and $337.5^{\circ}$, the temperature of the intermediate between the center and the side end is stationary, but the temperature of the center of bearing decrease about $2^{\circ} \mathrm{C}$. Moreover, as with the experimental results, the temperature of gas cavitation at $315^{\circ}$ and the temperature at $45^{\circ}$ and $90^{\circ}$ are almost unchanged.

Figure 11 shows the analytical results of the full-area of 

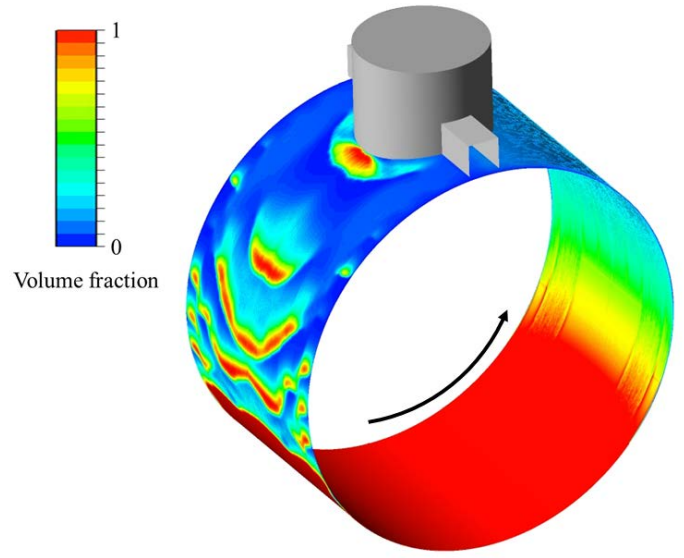

(a) Distribution of oil volume fraction

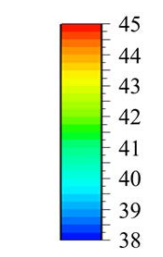

Temperature $T,{ }^{\circ} \mathrm{C}$

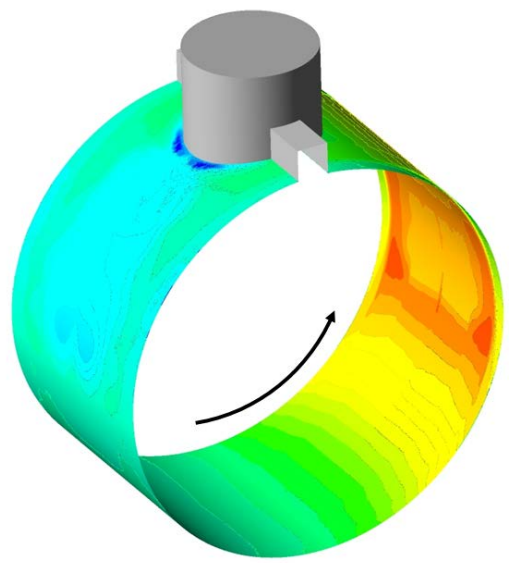

(b) Distribution of temperature

Fig. 11 Analysis results for temperature of starved lubrication condition

the bearing in the starved lubrication condition. From Fig. 11(a), the volume fraction of starved lubrication condition decreases at broad area compared to the volume fraction in the transition condition. The volume fraction of the wedge side increases at the center of bearing, while it is zero around the side end. The volume fraction of the inverse wedge side decreases with increasing of clearance, while it becomes zero at the near oil filler port. In comparison with the analytical results and experimental results, the trend of analysis results is same as the experiments. It is found that the increasing of temperature by the shear friction rises with the decreasing of clearance, while the maximum temperature exists at the near intermediate between the center and the side end. Moreover, the volume fraction of the intermediate of bearing is almost 0 , and as can be seen from the temperature result, this region is presumed to be the circulated the gas cavitation. From these results, it was found that the behavior of gas cavitation can be reproduced by CFD analysis. On the other hand, it is found that the temperature of the near oil filler port is about $38^{\circ} \mathrm{C}$, while it markedly decreases compared to the temperature of supply oil. Moreover, the temperature of the around center on bearing is smaller compared to the around intermediate between the center and the side end, while the different of both temperature become near. From this result, authors considered that internal flow of oil filler port influenced the temperature characteristics of starved lubrication condition. Thus, the volume fraction and temperature focused.
Figure 12 shows the analytical results of oil filler port. Figure 12(a) indicates the results of the internal oil filler port at the center of bearing width of starved lubrication condition (Fig. 11(a)). Figure 12(a,i) indicates the volume fraction, while Fig. 12(a,ii) indicates the temperature. Moreover, Fig. 12(b) indicates the analytical result in the front view of oil filler port. From Fig. 12(a), the temperature is high near the shaft, and the volume fraction decreases in that area. From the above, it is considered that the gas phase in this region is a circulating flow. In contrast, the gas phase exists the wide area in the inside of oil filler port, while the temperature of the gas phase is smaller than the temperature of supply oil. Moreover, it is found that the temperature of oil is commensurate with the temperature of supply oil or less than. Furthermore, the temperature of the gas phase from the bearing clearance is about $40^{\circ} \mathrm{C}$ at the center of

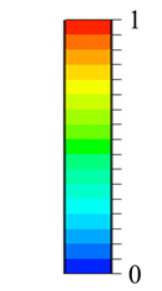

Volume fraction

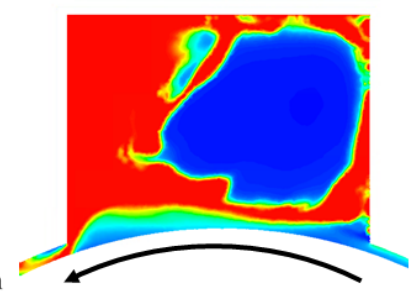

$(a, i)$ Distribution of oil volume fraction

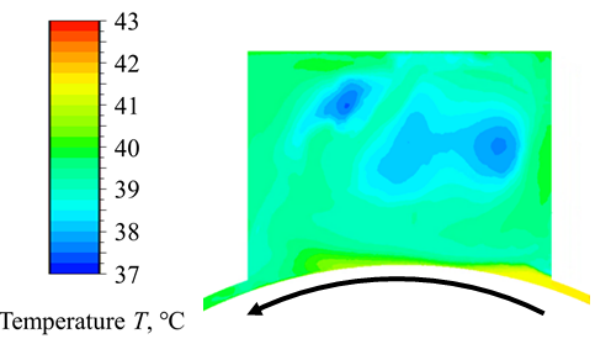

(a,ii) Distribution of temperature

(a) Results for wide center of bearing
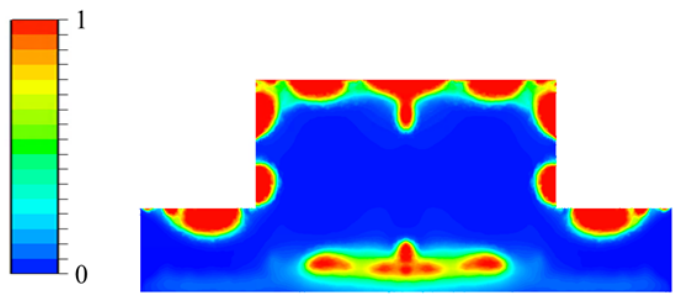

Volume fraction

(b,i) Distribution of oil volume fraction

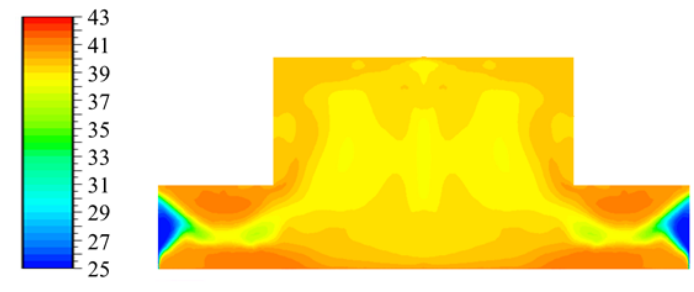

Temperature $T,{ }^{\circ} \mathrm{C}$

$(b, i i)$ Distribution of temperature

(b) Results for front view

Fig. 12 Analysis results for oil filler port in starved lubrication condition 
oil filler port. In Fig. 12(b), the gas phase exists the wide area in the inside of oil filler port as with Fig. 12(a), while it exists the oil supply groove. The temperature of gas phase around the side end of oil supply groove is the same as the ambient atmosphere temperature set on the analysis, thus it is found that outside air counterflow the oil supply groove. From these results, in the case of starved lubrication condition, it is considered that the outside air flows from the oil supply groove and the side end of bearing cooled the supplied oil and the circulating flow, thereby, the temperature of the center of bearing is controlled.

\section{Discussion}

As mentioned in the introduction, the oil film journal bearing under starved lubrication is suggested a local temperature rise due to the decrease in oil film thickness. However, in the case of the small bore oil film journal bearing with oil supply groove, it was found that the bearing temperature in both the transition condition and the starved lubrication condition does not rise as much as seizure or heat deformation occurs. In particular, because the bearing temperature in the transition condition is almost the same as the supply oil temperature, it is believed that the influence of the oil film temperature on the performance of journal bearing is exceedingly small. On the other hand, in the case of the starved lubrication condition, it was found that the temperature of the supply oil and the circulating oil at the inside the oil filler port are remarkably affected by the outside air. If the temperature around the bearing side end is higher than the temperature of supply oil, the temperature of the lubricated oil rises in the oil filler port, and if the oil film thickness becomes further thin due to the viscosity decrease, there is a risk of the bearing temperature locally rising there is. Therefore, the authors believe that the design of the oil film journal bearing assuming the starved lubrication condition necessitate the two-phase flow CFD analysis with considering the ambient temperature for the further safety design.

\section{Conclusions}

In this study, bearing temperatures were measured at positions at the bearing center and between the center and side end in the cases of oil whip, transition, and starved lubrication; the gas phase area in the bearing was viewed. Moreover, the temperature distribution in the journal bearing under the transition and starved lubrication conditions were analyzed using a two-phase flow CFD analysis for which the calculation conditions were decided based on the experiments. As results, it was found that the heat quantity caused by shear friction was small in the case of the transition condition, whereas the temperature inside the bearing was approximately the same as that of the supply oil, from both experimental and analytical perspectives. On the other hand, in the case of starved lubrication, it is believed that the air flowing out of the oil supply groove created a circulating flow, which cooled the side end of the bearing, thereby controlling the temperature at the center of the bearing. However, if the temperature of outside air is higher than the that of supply oil, there is a possibility that the bearing temperature will be higher than expected. Therefore, the authors believe that is would be better to consider temperature change in the design of the oil film journal bearing assuming starved lubrication condition.

\section{References}

[1] Li, D. F., Choy, K. C. and Allaire, P. E., "Stability and Transient Characteristics of Four Multilobe Journal Bearing Configurations," ASME Journal of Lubrication Technology, 102, 3, 1980, 291-298.

[2] Vaidyanathan, K. and Keith, T. G., "Numerical Prediction of Cavitation in Noncircular Journal Bearings," STLE Tribology Transactions, 32, 2, 1989, 215-224.

[3] Matsumoto, K. and Hashimoto, H., "Study on Improvement of Stability of Noncircular Journal Bearings (Stability Analysis for Various Bearing Orientation Angles)," Transactions of the Japan Society of Mechanical Engineers, Series C, 70, 692, 2004, 1199-1206 (in Japanese).

[4] Hashimoto, H. and Ochiai, M., "Experimental Study on the Stabilization of Small-Bore Journal Bearings by Controlling Starved Lubrication and Bearing Orientation Angle," ASME Journal of Tribology, 131, 1, 2009, 011705-011705-8.

[5] Hashimoto, H. and Ochiai, M., "Stabilization Method for Small-Bore Journal Bearings Utilizing Starved Lubrication," ASME Journal of Tribology, 132, 1, 2010, 011703-011703-7.

[6] Heshmat, H. and Pinkus, O., "Performance of Starved Journal Bearings with Oil Ring Lubrication," ASME Journal of Tribology, 107, 1, 1985, 23-31.

[7] Mitsui, J., "A Study of the Lubricant Film Characteristics of Journal Bearings:4th Report, Experimental Study on the Thermal Characteristics," Bulletin of JSME, 49, 438, 1982, 199-208.

[8] Mitsui, J., Hori, Y. and Tanaka, M., "Thermohydrodynamic Analysis of Cooling Effect of Supply Oil in Circular Journal Bearing," ASME Journal of Lubrication Technology, 105, 3, 1983, 414-420.

[9] Ikeuchi, K. and Mori, H., "Hydrodynamic Lubrication in Seals with Cavitation : 1st Report, Effect of Cavity Pressure On Lubricating Film," Bulletin of JSME, 25, 204, 1982, 1002-1007 (in Japanese).

[10] Ikeuchi, K. and Mori, H., "An Analysis of the Lubricating Films in Journal Barings -Effects of Oil Supply Condition on the Static Performance," Lubrication, 27, 7, 1982, 533-540 (in Japanese).

[11] Hatakenaka, K., Tanaka, M. and Suzuki, K., “Thermo-Hydrodynamic Performance of Journal Bearings with Partial Reverse Flow and Finger-Type Cavitation Being Considered," Journal of Japanese Society of Tribologists, 45, 8, 2000, 628-635 (in Japanese).

[12] Zhai, L. M., Luo, Y. Y. and Wang, Z. W., "Study about the Influence of Cavitation on the Dynamic Characteristics for the Sliding Bearing," IOP Conference Series, Materials Science and Engineering, 72, 2015, 042046.

[13] Dhande, D. Y. and Pande, D. W., “Multiphase Flow Analysis of Hydrodynamic Journal Bearing Using CFD Coupled Fluid Structure Interaction Considering Cavitation," Journal of King Saud University - Engineering Science, 2016.

[14] Sakai, F., Ochiai, M. and Hashimoto, H., "CFD Analysis of Journal Bearing with Oil Supply Groove Considering Two-Phase Flow," Proc. The 4th International Conference on Design Engineering and Science, 2017, 131.

[15] Sakai, F., Ochiai, M. and Hashimoto, H., "Stability Characteristics and CFD Analysis of Two-Phase Flow of Oil Film Journal Bearing Having Two Oil Filler Holes," Transactions of the JSME, 83, 848, 2017, 16-00457 (in Japanese).

[16] Brackbill, J. U., Kothe, D. B. and Zemach, C., "A Continuum Method for Modeling Surface Tension," Journal of computational physics, $100,2,1992,335-354$.

[17] Schnerr, G. H. and Sauer, J. "Physical and Numerical Modeling of Unsteady Cavitation Dynamics," In Proc. ICMF-2001, 4th International Conference on Multiphase Flow, New Orleans, 2001. 